\title{
Relationship between pulmonary function and bone mineral density in the Korean National Health and Nutrition Examination Survey
}

\author{
In Seon Lee ${ }^{1}$, Ah Young Leem ${ }^{1}$, Sang Hoon Lee ${ }^{1}$, Yumie Rhee ${ }^{2}$, Yoon $\mathrm{Ha}^{3}$, and Young Sam Kim ${ }^{1}$
}

${ }^{1}$ Division of Pulmonology, Department of Internal Medicine, ${ }^{2}$ Department of Internal Medicine, Endocrine Research Institute, ${ }^{3}$ Department of Neurosurgery, Severance Hospital, Yonsei University College of Medicine, Seoul, Korea

Received: October 30, 2014 Revised : December 20, 2014 Accepted: January 6, 2015

\section{Correspondence to}

Young Sam Kim, M.D.

Division of Pulmonology, Department of Internal Medicine, Severance Hospital, Yonsei University College of Medicine, 50-1 Yonseiro, Seodaemun-gu, Seoul 03722, Korea

Tel: +82-2-2228-1971

Fax: +82-2-393-6884

E-mail: YSAMKIM@yuhs.ac
Background/Aims: Osteoporosis is common in chronic obstructive pulmonary disease (COPD) patients. The relationship between osteoporosis and COPD has been primarily reported in patients with moderate to severe COPD, but there is no report in the general population. The aim of this study is to investigate the relationship between bone mineral density (BMD) and lung function in the general Korean population.

Methods: This study was based on data acquired from the Fourth and Fifth Korea National Health and Nutrition Examination Surveys (KNHANES IV and V), conducted from 2008 to 2010 . The study population included 4,501 subjects (aged $\geq$ 50 years) who underwent both spirometry and BMD. The study populations were divided into two groups by sex to correct for the effects of gender on BMD. All female participants were postmenopausal women.

Results: The BMD values of the femur neck, total femur, and L-spine tended to decrease with degree of airflow limitation in both genders. To correct confounding factors, data were analyzed and adjusted for age, body mass index, fat free mass index, body fat percentage, smoking amount, parathyroid hormone levels, daily calcium and phosphorus intake, and alkaline phosphatase (ALP) levels. While the BMD of the femur neck, total femur, and L-spine was reduced significantly as age and ALP increased, the correlation between airway obstruction and BMD of all regions disappeared in both genders.

Conclusions: In the general population aged 50 years and older, diminution of $\mathrm{BMD}$ is not associated with airway obstruction. Further investigation along other factors is needed to determine the possible role of pulmonary function and BMD.

Keywords: Respiratory function tests; Bone density; Osteoporosis

\section{INTRODUCTION}

Chronic obstructive pulmonary disease (COPD) is characterized by a progressive airflow limitation that is not fully reversible [1]. The degree of airflow limitation can be measured by spirometry and stratified using the Global Initiative for COPD (GOLD) guideline. COPD is a complex disease that affects not only lung function but also many other comorbidities, such as decreased physical activity, right ventricular heart failure, and decreased quality of life [2]. Osteoporosis is one of the comorbid diseases of COPD, especially in those with advanced airway limitation [3]. Between $35 \%$ and $72 \%$ of patients with COPD are reported to have osteopenia, and $36 \%$ to $60 \%$ 
of patients have osteoporosis [4-6]. Risk factors for osteoporosis in COPD patients that have been evaluated by previous studies are a low body mass index (BMI), a low fat free mass index (FFMI), and severe airflow limitation [7]. Whereas a large proportion of the COPD population is classified as having mild to moderate airway obstruction, most studies were evaluated in COPD patients with severe to very severe airflow limitation. The risk factor that may contribute to osteoporosis in patients with mild to moderate airway obstruction remains uncertain. Thus, the aim of the present study was to investigate whether bone mineral density (BMD) might correlate with lung function in the Korean population based on the Fourth and Fifth Korea National Health and Nutrition Examination Surveys (KNHANES IV and V).

\section{METHODS}

\section{Study participants}

A cross-sectional survey representative of the Korean general population (KNHANES IV to V) was carried out from 2007 to 2012 by the Division of Chronic Disease Surveillance, Korea Centers for Disease Control and Prevention. This study was based on data acquired from the second year (2008) of KNHANES IV to the first year (2010) of KNHANES V. The survey consisted of an evaluation of medical history, nutritional status, and health. After an initial interview at home, participants visited mobile centers, where they underwent an extensive physical examination, laboratory testing, BMD measurement, and spirometry.

A total of 29,965 adults over 20 years of age participated in the survey. The analysis included 4,501 subjects who were older than 50 years with complete data on both pulmonary function tests and BMD measurements. Regions were categorized as urban and rural. In the adult population, occupations were classified into two groups based on the different levels of sunlight exposure. Outdoor work included primary and secondary industries (agriculture, forestry and fishery, manual labor, engineering, assembling, and technical work), whereas indoor work consisted of tertiary industries, including managers, specialists, clerical workers, salespersons, service personnel, housewives, and students. Unemployed persons and others with unclassifiable work were grouped as indoor work. During the home interview, information was collected on a wide range of variables, including age, gender, smoking history, daily food intake, frequency of vitamin or mineral supplement intake, and frequency of undertaking a range of common physical activities. Dietary intakes of calcium (Ca) and phosphorous $(\mathrm{P})$ were estimated using a 24-hour dietary recall method. High-risk drinking was defined as "yes," when men consumed seven cups of alcohol or five cans of beer at one time, or when women consumed five cups of alcohol or three cans of beer at one time. Smoking status was categorized as "current smoker," "former smoker," and "never smoker." Never smokers were defined as those who smoked fewer than five packs during their entire lives. Exercise was indicated as "yes," when the subject exercised regularly at moderate or vigorous levels ( $>30$ minutes at a time and $>5$ times per week, in the case of moderate physical activity, and $>20$ minutes at a time and $>3$ times per week, in the case of vigorous physical activity). Women who had not menstruated for 1 year were considered postmenopausal. Body weight and anthropometrics were measured with light clothes. BMI was calculated as weight divided by height squared $\left(\mathrm{kg} / \mathrm{m}^{2}\right)$.

\section{Blood sampling}

Blood samples were collected after an overnight fast and were immediately refrigerated and transported in cold storage to the Central Testing Institute (Neodin Medical Institute, Seoul, Korea). Samples were analyzed within 24 hours after transportation. The concentrations of plasma glucose, serum calcium, phosphorus, creatinine, alkaline phosphatase (ALP), total cholesterol, and parathyroid hormone (PTH) were measured using standard laboratory techniques. The serum levels of 25-hydroxyvitamin $\mathrm{D}(25[\mathrm{OH}] \mathrm{D})$, which are considered the biomarker for vitamin D metabolic status, were measured using a radioimmunoassay (DISCOVERY-W, Hologic Inc., Bedford, MA, USA) equipped with APEX software (APEX Corporation Software, Pittsburg, PA, USA). PTH levels were determined by chemiluminescence (LIAISON, Diasorin Inc., Stillwater, MN, USA) using the N-tact PTH assay (Diasorin Inc.).

\section{Body composition and BMD}

Whole-body dual energy X-ray absorptiometry (DXA) 
was performed with a BDR Discovery fan beam densitometer (Hologic Inc.) located in the mobile examination centers, and analyses were performed using Hologic Discovery software version 13.1. BMD was expressed as an absolute value and as a T-score (standard deviations from a young, sex-specific reference mean BMD). Osteopenia is defined as a T-score between -1.0 and -2.5 . Osteoporosis is defined as a T-score below -2.5. Percentage body fat (fat mass / total mass $\times 100$ ) as well as BMD at the lumbar spine (L1-4) and proximal femur (total hip region) were measured using DXA. FFMI was calculated from DXA-measured fat-free mass in kilograms divided by height in meters squared $\left(\mathrm{kg} / \mathrm{m}^{2}\right)$.

\section{Pulmonary function test}

Spirometry was performed by specially trained technicians according to the 2005 American Thoracic Society and European Respiratory Society recommendations, using a dry rolling seal spirometer (SensorMedics Model 1022, Sensor Medics, Palm Springs, CA, USA). We analyzed only data from subjects with acceptable spirometry performance. Spirometric values were prebronchodilator measurements, and relative values were expressed as the percentage predicted from reference values. Values used in the study were forced vital capacity (FVC), forced expiratory volume in 1 second $\left(\mathrm{FEV}_{1}\right)$, and $\mathrm{FEV}_{1}$ to FVC ratio $\left(\mathrm{FEV}_{1} / \mathrm{FVC}\right)$. We categorized the subjects by severity of airflow obstruction. Airway obstruction was deemed to be present when the $\mathrm{FEV}_{1} / \mathrm{FVC}$ was less than 0.7. When the $\mathrm{FEV}_{1} / \mathrm{FVC}$ was greater than 0.7 , the subjects were categorized as "no obstruction." Severity of airway obstruction was determined on the basis of $\mathrm{FEV}_{1}$ : mild obstruction, $\mathrm{FEV}_{1} \geq 80 \%$ of predicted value; moderate obstruction, $\mathrm{FEV}_{1}<80 \%$ and $\mathrm{FEV}_{1} \geq 50 \%$ of predicted value; and severe obstruction $\mathrm{FEV}_{1}<50 \%$ of predicted value.

\section{Statistical analyses}

Statistical analyses were performed using SAS version 9.2 (SAS Institute Inc., Cary, NC, USA). To correct the effects of gender on BMD, study participants were divided into two groups by sex and then separately analyzed. BMI was further divided into four categories, which corresponded to the International Classification suggested by the World Health Organization: underweight (BMI $<18.5$ ), normal (18.5 $\leq \mathrm{BMI}<25)$, overweight $(25 \leq \mathrm{BMI}$
<30), and obese (BMI $\geq 30)$. Serum $25(\mathrm{OH}) \mathrm{D}$ levels were also divided into quartiles: < 16.69, 16.79 to $21.44,21.14$ to 26.32 , and $\geq 26.32 \mathrm{ng} / \mathrm{mL}$ cutoff values were used for men; < $13.75,13.75$ to $17.90,17.90$ to 23.42 , and $\geq 23.42 \mathrm{ng} /$ $\mathrm{mL}$ cutoff values were used for women. To compare the baseline characteristics between males and females, the Student $t$ test or the chi-square test was used for comparisons. Bivariate correlation analysis was used to evaluate the association between possible predictive factors and BMD. Multivariate linear regression analysis was used to evaluate the relationships between BMD and selected covariates that are considered clinically important risk factors for osteopenia. Continuous variables were expressed as the mean $\pm \mathrm{SD}$. All tests were two-sided, and $p<0.05$ was considered statistically significant.

\section{RESULTS}

The baseline demographics of the study populations are given in Table 1. The subjects were comprised of 2,100 (46.7\%) males and 2,401 (53.3\%) females. The mean age of males was 61.9 years, and the mean age of females was 62.8 years. Most participants were in their $50 \mathrm{~s}$. The mean BMI was $24.0 \mathrm{~kg} / \mathrm{m}^{2}$ in males and $24.3 \mathrm{~kg} / \mathrm{m}^{2}$ in females. Most subjects were of normal weight in both genders, followed by being overweight. All female subjects were postmenopausal. In both genders, the proportion living in an urban area was about $68.0 \%$. The proportion of those with high-risk alcohol intake was $22.0 \%$ in males and $3.2 \%$ in females. Of males, $17.7 \%$ were never smokers compared to $92.4 \%$ of female. The proportion of the regular exercise "yes" group was $28.3 \%$ in males and $22.8 \%$ in females (Table 1 ).

The mean $25(\mathrm{OH}) \mathrm{D}$ level was $22.0 \mathrm{ng} / \mathrm{mL}$ in males and $19.1 \mathrm{ng} / \mathrm{mL}$ in females. The mean $\mathrm{FEV}_{1}$ (\% of predicted value) was $88.6 \%$ in males and $94.5 \%$ in females. While the no airway obstruction group comprised $71.8 \%$ of subjects, the mild obstruction group comprised $13.6 \%$ and the moderate to severe obstruction group was $14.6 \%$ of males; most female participants belonged to the no obstruction group (91.3\%), followed by the moderate to severe obstruction group (5.2\%) and the mild obstruction group (3.5\%) (Table 2).

The subjects who lived in urban areas appeared to have lower BMDs than those dwelling in rural areas, but 
Table 1. Baseline demographics of subjects

\begin{tabular}{|c|c|c|}
\hline Characteristic & Male $(\mathrm{n}=2,100)$ & Female $(\mathrm{n}=2,401)$ \\
\hline Age, yr & $61.9 \pm 8.1$ & $62.8 \pm 8.0$ \\
\hline $50-59$ & $904(43.1)$ & $948(39.5)$ \\
\hline $60-69$ & $772(36.8)$ & $917(38.2)$ \\
\hline $70-79$ & $390(18.6)$ & $492(20.5)$ \\
\hline$\geq 80$ & $34(1.6)$ & $44(1.8)$ \\
\hline Body mass index, $\mathrm{kg} / \mathrm{m}^{2}$ & $24.0 \pm 2.8$ & $24 \cdot 3 \pm 3.0$ \\
\hline$<18.5$ & $48(2.3)$ & $41(1.7)$ \\
\hline 18.5 to $<25$ & $1,312(62.5)$ & $640(26.6)$ \\
\hline 25 to $<30$ & $705(33.6)$ & $831(34.6)$ \\
\hline$\geq 30$ & $35(1.7)$ & $84(3 \cdot 5)$ \\
\hline \multicolumn{3}{|l|}{ Region } \\
\hline Urban & $1,414(67 \cdot 3)$ & $1,651(68.8)$ \\
\hline Rural & $686(32.7)$ & $750(31.2)$ \\
\hline \multicolumn{3}{|l|}{ Occupation } \\
\hline Outdoor work & $986(47 \cdot 4)$ & $691(28.9)$ \\
\hline Indoor work & $1,095(52.6)$ & $1,704(71.1)$ \\
\hline \multicolumn{3}{|l|}{ High-risk alcohol intake } \\
\hline Yes & $359(22.0)$ & $37(3.2)$ \\
\hline No & $1,276(78.0)$ & $1,106(96.8)$ \\
\hline Smoking amount, pack-yr & $23 \cdot 3 \pm 21.0$ & $0.9 \pm 4.8$ \\
\hline Current smoker & $1,319(63.1)$ & $157(6.6)$ \\
\hline Former smoker & $401(19.2)$ & $25(1.0)$ \\
\hline Never smoker & $371(17.7)$ & $2,212(92.4)$ \\
\hline \multicolumn{3}{|l|}{ Exercise } \\
\hline Yes & $591(28.3)$ & $544(22.8)$ \\
\hline No & $1,500(71.7)$ & $1,846(77.2)$ \\
\hline
\end{tabular}

Values are presented as mean \pm SD or number (\%).

this trend was statistically significant only in females. The indoor work group was shown to have significantly higher BMDs of the lumbar spine than the outdoor work group in both genders, whereas there was no significant correlation between occupation and BMD of the femur. The regular exercise "yes" group appeared to have higher BMDs than the "no" exercise group in both males and females, except for BMDs of the L-spine (Table 3).

The BMD level was lower with increased age, number of smoking pack-years, and levels of PTH and ALP, whereas it was significantly higher with increased BMI, total FFMI, body fat percentage, daily calcium intake, and daily phosphorus intake in both genders. The levels of $25(\mathrm{OH}) \mathrm{D}$ did not correlate with BMDs of the femur neck, total femur, or lumbar spine. The $\mathrm{FEV}_{1} / \mathrm{FVC}$ ratio was positively correlated with BMDs of all bone regions in both males and females, except for the BMD of the L-spine in males with $\mathrm{FEV}_{1} / \mathrm{FVC}$. In males, $\mathrm{FEV}_{1}$ (\% of predicted value) was increased with increased BMD of total femur, whereas the $\mathrm{FEV}_{1}$ (\% of predicted value) did not correlate with any region in females. The FVC (\% of predicted value) was lower with increasing BMDs of the lumbar spine in males, whereas the FVC (\% of predicted value) was higher with increasing BMDs of the femur neck and total femur in females. BMDs of other regions did not show a significant correlation with FVC (\% of predicted value) (Table 4). 
Table 2. Baseline characteristics of subjects

\begin{tabular}{|c|c|c|}
\hline Characteristic & Male $(n=2,100)$ & Female $(\mathrm{n}=2,401)$ \\
\hline \multicolumn{3}{|l|}{ Anthropometric data } \\
\hline Total FFMI, kg/m² & $18.3 \pm 1.8$ & $15 \cdot 7 \pm 1.5$ \\
\hline Body fat, \% & $22.6 \pm 4.9$ & $34.6 \pm 5.2$ \\
\hline \multicolumn{3}{|l|}{ Laboratory data } \\
\hline Parathyroid hormone, mg/dL & $67.7 \pm 27.1$ & $69.7 \pm 31.8$ \\
\hline${ }_{25}(\mathrm{OH}) \mathrm{D}, \mathrm{ng} / \mathrm{mL}$ & $22.0 \pm 7.4$ & $19.1 \pm 7.2$ \\
\hline Lowest & $13.4 \pm 2.4$ & $11.0 \pm 2.1$ \\
\hline Lowest to intermediate & $18.9 \pm 1.3$ & $15.8 \pm 1.2$ \\
\hline Intermediate to highest & $23.6 \pm 1.5$ & $20.5 \pm 1.5$ \\
\hline Highest & $31.9 \pm 4.7$ & $29.1 \pm 4.9$ \\
\hline Alkaline phosphatase, mg/dL & $239.2 \pm 72.9$ & $255 \cdot 4 \pm 78.3$ \\
\hline \multicolumn{3}{|l|}{ Nutritional status } \\
\hline Ca intake, mg/dL & $557 \cdot 6 \pm 355 \cdot 4$ & $433.7 \pm 417 \cdot 7$ \\
\hline $\mathrm{P}$ intake, $\mathrm{mg} / \mathrm{dL}$ & $1,297.1 \pm 515 \cdot 9$ & $966.1 \pm 440.8$ \\
\hline \multicolumn{3}{|l|}{ Respiratory parameters } \\
\hline FVC, \% of predicted value & $89.5 \pm 12.5$ & $92.8 \pm 12.8$ \\
\hline $\mathrm{FEV}_{1}, \%$ of predicted value & $88.6 \pm 15.0$ & $94.5 \pm 14.6$ \\
\hline $\mathrm{FEV}_{1} / \mathrm{FVC}$ & $0.7 \pm 0.1$ & $0.8 \pm 0.1$ \\
\hline \multicolumn{3}{|l|}{ Severity of airway obstruction } \\
\hline None & $1,508(71.8)$ & $2,191(91.3)$ \\
\hline Mild & $286(13.6)$ & $85(3.5)$ \\
\hline Moderate & $267(12.7)$ & $117(4 \cdot 9)$ \\
\hline Severe & $39(1.9)$ & $8(0.3)$ \\
\hline
\end{tabular}

Values are presented as mean $\pm \mathrm{SD}$ or number (\%).

FFMI, fat free mass index; $25(\mathrm{OH}) \mathrm{D}$, 25-hydroxyvitamin D; FVC, forced vital capacity; $\mathrm{FEV}_{1}$, forced expiratory volume in 1 second.

The proportions of patients with osteopenia and osteoporosis gradually increased according to the severity of airway obstruction in both males and females. In severe obstruction, the proportion of osteoporosis was $21 \%$ of males and $38 \%$ of females. Indeed, all female participants in the severe airway obstruction group had osteopenia and osteoporosis. The proportion of patients with osteoporosis was higher in females than in males at all stages of airway obstruction (Fig. 1).

The total BMDs at different regions of the femur and lumbar spine in the "obstruction" group were significantly lower than for the "no obstruction" group in both genders, except for the total BMD of the lumbar spine in males (Fig. 2).

To adjust confounding factors, data were analyzed by multivariate linear regression analysis adjusted for age,
BMI, total FFMI, body fat percentage, smoking amount, exercise, PTH, $25(\mathrm{OH}) \mathrm{D}$, daily intake of calcium and phosphorus, and ALP. Results revealed that BMDs of the femur neck, total femur, and lumbar spine in both genders were reduced significantly as age increased. When daily calcium intake increased, BMDs of all regions increased significantly in males. As ALP increased, BMDs of all regions s increased in both males and females. Severity of airway obstruction did not show a significant correlation with BMDs of any region in males or females (Table 5).

\section{DISCUSSION}

In this population based, cross-sectional study, BMD 
Table 3. Bone mineral density in males and females

\begin{tabular}{|c|c|c|c|c|c|c|}
\hline \multirow{2}{*}{ Variable } & \multicolumn{3}{|c|}{ Male $(n=2,100)$} & \multicolumn{3}{|c|}{ Female $(n=2,401)$} \\
\hline & Femur neck & Total femur & Lumbar spine & Femur neck & Total femur & Lumbar spine \\
\hline \multicolumn{7}{|l|}{ Region } \\
\hline Urban & 0.755 & 0.940 & 0.937 & $0.623^{\mathrm{a}}$ & $0.775^{\mathrm{a}}$ & $0.784^{b}$ \\
\hline Rural & 0.762 & 0.939 & 0.956 & 0.635 & 0.788 & 0.821 \\
\hline \multicolumn{7}{|l|}{ Occupation } \\
\hline Outdoor work & 0.761 & 0.940 & $0.936^{\mathrm{a}}$ & 0.635 & 0.790 & $0.795^{\mathrm{b}}$ \\
\hline Indoor work & $0.75^{8}$ & 0.938 & 0.962 & 0.629 & 0.781 & 0.815 \\
\hline \multicolumn{7}{|c|}{ High-risk alcohol intake } \\
\hline Yes & 0.768 & 0.948 & 0.950 & 0.666 & 0.815 & 0.827 \\
\hline No & 0.763 & 0.942 & 0.953 & 0.651 & 0.804 & 0.824 \\
\hline \multicolumn{7}{|l|}{ Exercise } \\
\hline Yes & $0.772^{\mathrm{a}}$ & $0.954^{b}$ & 0.953 & $0.645^{\mathrm{b}}$ & $0.801^{b}$ & 0.818 \\
\hline No & 0.755 & 0.933 & 0.949 & 0.627 & 0.779 & 0.806 \\
\hline
\end{tabular}

Values are presented as mean.

$\mathrm{a} p<0.05$.

${ }^{b} p<0.001$.

Table 4. Correlation coefficients between clinical characteristics, biochemical characteristics, and bone mineral density

\begin{tabular}{|c|c|c|c|c|c|c|}
\hline \multirow[b]{2}{*}{ Characteristic } & \multicolumn{3}{|c|}{ Male $(\mathrm{n}=2,100)$} & \multicolumn{3}{|c|}{ Female $(\mathrm{n}=2,401)$} \\
\hline & $\begin{array}{c}\text { Femur neck } \\
\text { BMD }\end{array}$ & $\begin{array}{l}\text { Total femur } \\
\text { BMD }\end{array}$ & $\begin{array}{c}\text { Lumbar spine } \\
\text { BMD }\end{array}$ & $\begin{array}{c}\text { Femur neck } \\
\text { BMD }\end{array}$ & $\begin{array}{l}\text { Total femur } \\
\text { BMD }\end{array}$ & $\begin{array}{c}\text { Lumbar spine } \\
\text { BMD }\end{array}$ \\
\hline Age, yr & $-0.34^{\mathrm{a}}$ & $-0.31^{\mathrm{a}}$ & $-0.09^{\mathrm{a}}$ & $-0.53^{\mathrm{a}}$ & $-0.50^{\mathrm{a}}$ & $-0.36^{\mathrm{a}}$ \\
\hline Body mass index, kg/m² & $0.36^{\mathrm{a}}$ & $0.42^{\mathrm{a}}$ & $0.33^{\mathrm{a}}$ & $0.21^{\mathrm{a}}$ & $0.26^{\mathrm{a}}$ & $0.24^{\mathrm{a}}$ \\
\hline Total FFMI, kg/m² & $0.41^{\mathrm{a}}$ & $0.47^{\mathrm{b}}$ & $0.31^{\mathrm{b}}$ & $0.22^{\mathrm{a}}$ & $0.27^{\mathrm{a}}$ & $0.21^{\mathrm{a}}$ \\
\hline Body fat, \% & $0.06^{b}$ & $0.08^{b}$ & $0.15^{b}$ & $0.09^{\mathrm{a}}$ & $0.11^{\mathrm{a}}$ & $0.14^{\mathrm{a}}$ \\
\hline Smoking amount, pack-yr & $-0.05^{b}$ & $-0.07^{b}$ & $-0.05^{b}$ & $-0.09^{a}$ & $-0.09^{\mathrm{a}}$ & $-0.05^{b}$ \\
\hline PTH, mg/mL & $-0.06^{b}$ & $-0.07^{b}$ & -0.03 & $-0.08^{a}$ & $-0.08^{a}$ & 0.00 \\
\hline${ }_{25}(\mathrm{OH}) \mathrm{D}, \mathrm{ng} / \mathrm{mL}$ & 0.01 & 0.01 & -0.01 & -0.01 & -0.01 & -0.02 \\
\hline Ca intake, mg/dL & $0.21^{\mathrm{a}}$ & $0.17^{\mathrm{a}}$ & $0.11^{\mathrm{a}}$ & $0.10^{\mathrm{a}}$ & $0.11^{\mathrm{a}}$ & $0.09^{\mathrm{a}}$ \\
\hline P intake, mg/dL & $0.22^{\mathrm{a}}$ & $0.19^{\mathrm{a}}$ & $0.09^{\mathrm{a}}$ & $0.16^{\mathrm{a}}$ & $0.16^{\mathrm{a}}$ & $0.12^{\mathrm{a}}$ \\
\hline $\mathrm{ALP}, \mathrm{mg} / \mathrm{dL}$ & $-0.20^{\mathrm{a}}$ & $-0.21^{\mathrm{a}}$ & $-0.18^{\mathrm{a}}$ & $-0.12^{\mathrm{a}}$ & $-0.14^{\mathrm{a}}$ & $-0.15^{\mathrm{a}}$ \\
\hline FVC \% of predicted & 0.02 & 0.02 & $-0.09^{\mathrm{a}}$ & $0.07^{\mathrm{a}}$ & $0.04^{\mathrm{a}}$ & -0.01 \\
\hline $\mathrm{FEV}_{1} \%$ of predicted & 0.03 & $0.05^{\mathrm{b}}$ & $-0.04^{b}$ & 0.00 & 0.00 & -0.04 \\
\hline $\mathrm{FEV}_{1} / \mathrm{FVC}$ & $0.14^{\mathrm{a}}$ & $0.15^{\mathrm{a}}$ & 0.04 & $0.15^{\mathrm{a}}$ & $0.17^{\mathrm{a}}$ & $0.10^{\mathrm{a}}$ \\
\hline
\end{tabular}

BMD, bone mineral density; FFMI, fat free mass index; PTH, parathyroid hormone; 25(OH)D, 25-hydroxyvitamin D; ALP, alkaline phosphatase; FVC, forced vital capacity; $\mathrm{FEV}_{1}$, forced expiratory volume in 1 second.

${ }^{\mathrm{a}} \mathrm{p}<0.001$.

${ }^{\mathrm{b}} \mathrm{p}<0.05$.

was not lower significantly with decreased pulmonary function in the general population after adjustment. Associations between pulmonary function and osteoporo- sis have been conflicting in different studies [7-9]. A meta-analysis reported that the prevalence of osteoporosis was higher in COPD patients than in healthy subjects 

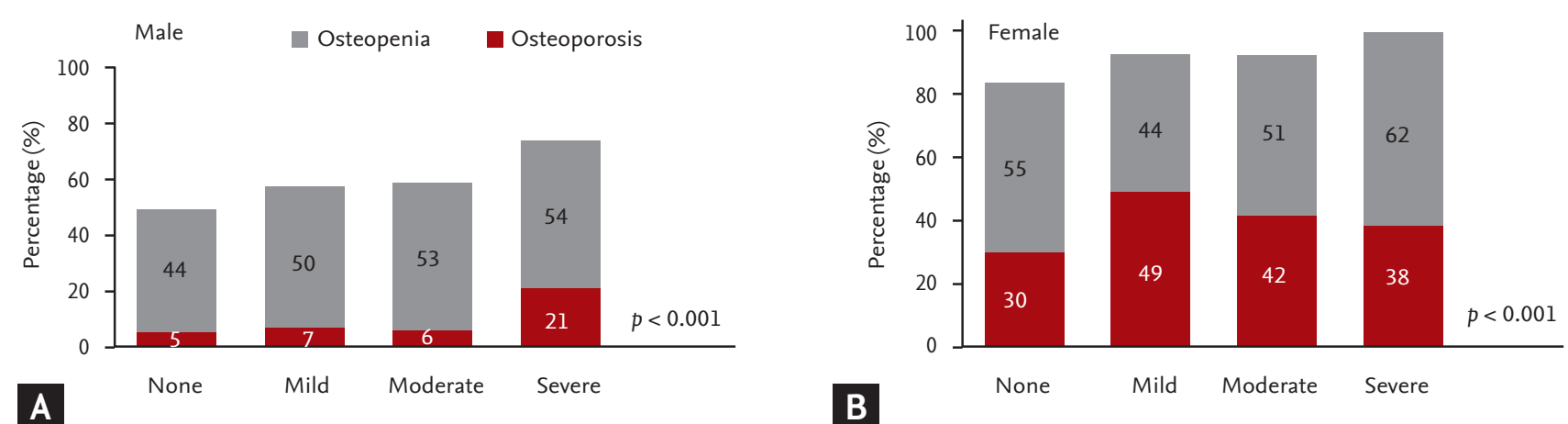

Figure 1. Proportion of osteoporosis and osteopenia according to severity of airway obstruction in (A) male and (B) female.
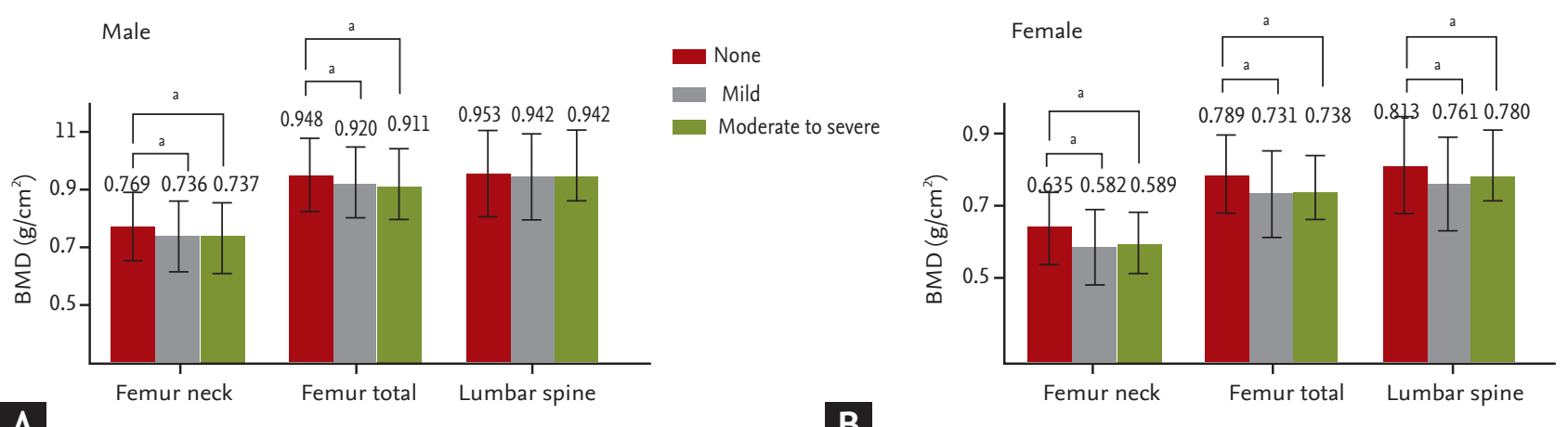

Figure 2. Bone mineral density (BMD) at the lumbar spine and hip regions according to the severity of airway obstruction in (A) male and (B) female. Values are presented as mean \pm SD. ${ }^{\text {a }}$ Significant difference $p<0.001$.

[7]. Some researchers have reported that BMDs of the total hip and femoral neck significantly decreased with impairments in lung function [8]. As airway obstruction becomes more severe, the proportion of patients with osteoporosis increases [9]. Indeed, one study proposed that the presence of COPD is one of the parameters for increasing risk of osteoporosis in males, but many studies investigated COPD patients who came to the hospital for treatment, so study populations have consisted of moderate to severe airway obstruction. Shepherd et al. [10] used data from the National Health and Nutrition Examination Survey III of the U.S. population. They validated the Male Osteoporosis Risk Estimation Score (MORES) that included three variables-age, weight, and history of COPD all showed excellent predictive value for developing osteoporosis [10]. Lower $\mathrm{FEV}_{1}$ showed a correlation with the degree of osteopenia regardless of glucocorticoid use, although for comparable degrees of pulmonary impairment, the subjects treated with prednisone had more frequent osteopenia. Indeed, a cross-sectional study investigated healthy women, and the BMDs of the lumbar spine and proximal femur revealed a significant positive correlation with $\mathrm{FEV}_{1}$ in postmenopausal women [11]. Two general population-based studies suggested that $\mathrm{FEV}_{1}$ becomes higher with increasing BMD in middle-aged to older people. Additionally, this association remained significant after adjusting for age, weight, height, respiratory disease, cardiovascular diseases, smoking status, and medical history of steroid use and hormone replacement therapy. However, two studies did not adjust for daily vitamin intake, and it is known that serum $25(\mathrm{OH}) \mathrm{D}, \mathrm{PTH}$, and ALP levels can all influence BMD. These particular studies also did not quantify smoking amount or use of corticosteroids, and these variables may have dose-related influences on BMD or pulmonary function. Physical activity, alcohol consumption, and nutritional status were also not explored [8,12]. Sin et al. [13] also analyzed 
Table 5. Coefficients between clinical characteristics, biochemical characteristics, and bone mineral density after multiple linear regression analysis in males and females

\begin{tabular}{|c|c|c|c|c|c|c|}
\hline \multirow[b]{2}{*}{ Characteristic } & \multicolumn{3}{|c|}{ Male $(\mathrm{n}=2,100)$} & \multicolumn{3}{|c|}{ Female $(\mathrm{n}=2,401)$} \\
\hline & $\begin{array}{c}\text { Femur neck } \\
\text { BMD }\end{array}$ & $\begin{array}{c}\text { Total femur } \\
\text { BMD }\end{array}$ & $\begin{array}{c}\text { Lumbar spine } \\
\text { BMD }\end{array}$ & $\begin{array}{c}\text { Femur neck } \\
\text { BMD }\end{array}$ & $\begin{array}{l}\text { Total femur } \\
\text { BMD }\end{array}$ & $\begin{array}{c}\text { Lumbar spine } \\
\text { BMD }\end{array}$ \\
\hline Age, yr & $-0.00285^{\mathrm{a}}$ & $-0.00259^{\mathrm{a}}$ & -0.00005 & $-0.00638^{\mathrm{a}}$ & $-0.00665^{\mathrm{a}}$ & $-0.00595^{\mathrm{a}}$ \\
\hline Body mass index, $\mathrm{kg} / \mathrm{m}^{2}$ & 0.00967 & 0.01030 & 0.00202 & 0.00096 & -0.00202 & -0.00052 \\
\hline Total FFMI, kg/m² & 0.00895 & 0.01439 & 0.02249 & $0.01456^{b}$ & $0.02474^{b}$ & 0.02110 \\
\hline Body fat, \% & -0.00111 & -0.00064 & 0.00369 & 0.00134 & 0.00301 & 0.00346 \\
\hline Smoking amount, pack-yr & 0.00007 & -0.00002 & -0.00030 & -0.00574 & -0.00099 & -0.00036 \\
\hline Exercise & 0.00263 & 0.00475 & -0.01493 & 0.00224 & 0.00435 & 0.00287 \\
\hline PTH, mg/mL & -0.00014 & -0.00019 & -0.00020 & $-0.00019^{b}$ & $-0.00023^{b}$ & 0.00017 \\
\hline${ }_{25}(\mathrm{OH}) \mathrm{D}, \mathrm{ng} / \mathrm{mL}$ & -0.00019 & -0.00014 & -0.00074 & -0.00019 & -0.00024 & -0.00058 \\
\hline Ca intake, mg/dL & $0.00003^{b}$ & $0.00003^{b}$ & $0.00003^{b}$ & 0.000003 & 0.000009 & 0.000011 \\
\hline P intake, mg/dL & $0.00002^{b}$ & 0.00001 & 0.000004 & 0.000008 & 0.000003 & 0.000006 \\
\hline $\mathrm{ALP}, \mathrm{mg} / \mathrm{dL}$ & $-0.00024^{a}$ & $-0.00026^{a}$ & $-0.00029 a$ & $-0.00014 a$ & $-0.00020 \mathrm{a}$ & $-0.00026^{\mathrm{a}}$ \\
\hline \multicolumn{7}{|l|}{ Airway obstruction } \\
\hline None & - & - & - & - & - & - \\
\hline Mild & 0.00223 & 0.01493 & 0.00854 & 0.00093 & 0.00857 & 0.01500 \\
\hline Moderate to severe & 0.00768 & 0.00964 & 0.02127 & -0.00851 & -0.01130 & 0.00436 \\
\hline
\end{tabular}

Regression models were adjusted for age, body mass index, FFMI, body fat percentage, smoking amount, serum 25(OH)D, PTH, ALP, daily calcium intake, daily phosphorus intake, exercise, and severity of airway obstruction.

BMD, bone mineral density; FFMI, fat free mass index; PTH, parathyroid hormone; 25(OH)D, 25-hydroxyvitamin D; ALP, alkaline phosphatase.

${ }^{\mathrm{a}} \mathrm{p}<0.001$.

${ }^{\mathrm{b}} \mathrm{p}<0.05$.

data from Caucasian participants in the Third National Health and Nutrition Examination Survey, conducted in the United States between 1988 and 1994. Airflow obstruction was associated with increased odds of osteoporosis compared with the no airflow obstruction group (odds ratio, 1.9; 95\% confidence interval, 1.4 to 2.5 ). The risk of osteoporosis increased in a linear "severity-dependent" fashion [13]. These authors used quantified smoking status (pack-years) and surveyed medication usage (bronchodilators, inhaled or intranasal corticosteroids, estrogens, diuretics, etc.). BMD levels increased gradually with age, showing a peak in the third decade of life, and gradually decreasing thereafter. Their study populations were older than 20 years, and menopause in women was not reflected.

Contrary to many other studies, some researchers have failed to find statistically significant difference between BMD values of COPD and non-COPD groups $[14,15]$. Twenty-eight male COPD patients with a moder- ate degree of airway obstruction and 20 male volunteer subjects with normal lung function participated in the study. There was no difference in baseline characteristics (age, BMI, dietary parameters) and the level of physical activity between the two groups, except for smoking history. There was no statistically significant difference in the prevalence of osteoporosis between COPD patients and the control healthy group [15]. These discrepancies may be derived from differences in the characteristics of subjects among the studies, such as race, age, gender, menopausal status, history of corticosteroid exposure, and other anthropometric variables. These parameters can contribute to the pathophysiology of osteoporosis in COPD patients [15].

Our data from a large population-based sample with or without airflow obstruction are a nationally representative sample, as conducted by KNHANES, compared with other studies in which the data were collected from a local hospital. Thus, a different proportion of 
patients with severe lung function impairment is one reason for the conflicting results. As we analyzed the age group older than 50 years, we eliminated the influences of premenopause and inconsistencies associated with aging on BMD [9]. Our data contained more detailed information on the demographic and socioeconomic factors, such as complete smoking history and physical activities, as measured by weekly, quantitative energy consumption, so we could analyze the data more deeply and could adjust for various confounding factors. After adjusting for confounding factors, including age, BMI, total FFMI, body fat percentage, smoking amount, exercise, PTH, 25(OH)D, daily intake of calcium and phosphorus, and ALP, the association between airway obstruction and BMD disappeared. These results suggest that the high prevalence of osteoporosis in COPD patients is associated with other factors and not with an impairment of lung function. The strengths of this study, compared with most previous studies of lung function and BMD, include a larger number of participants and the rigorous centralized quality control of the BMD scans. These factors may account for the discrepancy among the studies.

We explored possible contributions of body composition, such as FFMI and body fat percentage. Osteoporosis can be influenced by low body weight, fat mass or fat-free mass, and FFMI, depending on age, sex, and menopausal status. Additionally, body composition changes can cause complications, including impaired respiratory muscle function and loss of skeletal muscle mass with reduced force generation. Many researchers have suggested that FFMI is associated with disease severity, exercise capacity, quality of life, and mortality in patients with COPD [16-18]. The linkage between loss of FFMI and BMD may be a causative mechanism that can explain osteoporosis in COPD patients. Previous analyses of data from KNHANES IV to V showed that both BMI and FFMI values decreased significantly in subjects with severe airway obstruction, whereas those subjects with mild to moderate airway obstruction had values equivalent to those of the control group.

Several limitations of this study deserve consideration. We used 25(OH)D levels for analysis, which were found to be associated with lung function from the Third National Health and Nutrition Examination Survey in the USA [19]. A previous analysis of the KNHANES III data showed a relationship between serum concentrations of $25(\mathrm{OH}) \mathrm{D}$ and lung function. Contrary to previous studies, our analysis from the KNHANES III and IV data did not show such an association. A possible explanation is that these discordances may be derived from differences in age of subjects, season, region, and exposure to sunlight, which are important determinants of BMD. We did not investigate each subject's amount of sunlight exposure. We assumed that those who work outdoors would have more sunlight exposure, but our data revealed conflicting results between occupation and BMD in each region. Thus, we could not estimate the amount of sunlight exposure. These differences may influence the relationship between BMD and lung function.

The measurements of BMD using DXA may be confounded by several factors [20]. In particular, measurements of lumbar spine BMD using DXA becomes less useful with increasing age due to confounding effects, such as vertebral collapse, osteophytes, and aortic calcification, all leading to a "pseudo-normalizing" of the BMD. Different calculating patterns have been used for each DXA scan, and thus, these discrepancies should each be considered [21].

The data did not contain information about current medications, such as steroid use, dosage, and duration. Although the effects of inhaled corticosteroids on osteoporosis and fractures remain controversial, systemic corticosteroids could affect BMD by decreasing new bone formation while increasing bone loss. Indeed, the rate of bone loss correlates loosely with the daily dose and duration of therapy [22]. In addition, pharmacological treatments of osteoporosis such as bisphosphonates can influence BMD. Smith et al. [23] suggested that alendronate improves significantly T- and Z-scores for lumbar spine BMD, but not for hip BMD, in patients with asthma or COPD. Further studies are needed to understand the effects on BMD of corticosteroids and medications for osteoporosis.

In conclusion, BMD appeared lower in subjects with airflow limitation on pulmonary function tests in the general Korean population aged 50 years and older. Osteopenia and osteoporosis are more common in adult with airflow limitation. However, the results of this study suggest that lower BMD levels are not associated with deficits in lung function after adjusting for confounding factors. To determine the association between 
impaired lung function and osteoporosis, more prospectively controlled studies are needed.

\section{KEY MESSAGE}

1. In the general Korean population aged 50 years and older, osteopenia and osteoporosis are more common in adults with airflow limitations.

2. After adjusting for confounding factors, the association between pulmonary function and bone mineral density disappeared. The high prevalence of osteoporosis in chronic obstructive pulmonary disease patients is associated with other factors but not with impairments in pulmonary function.

\section{Conflict of interest}

No potential conflict of interest relevant to this article was reported.

\section{REFERENCES}

1. Rabe KF, Hurd S, Anzueto A, et al. Global strategy for the diagnosis, management, and prevention of chronic obstructive pulmonary disease: GOLD executive summary. Am J Respir Crit Care Med 2007;176:532-555.

2. Katsura H, Kida K. A comparison of bone mineral density in elderly female patients with COPD and bronchial asthma. Chest 2002;122:1949-1955.

3. Yawn BP, Kaplan A. Co-morbidities in people with COPD: a result of multiple diseases, or multiple manifestations of smoking and reactive inflammation? Prim Care Respir J 2008;17:199-205.

4. Iqbal F, Michaelson J, Thaler L, Rubin J, Roman J, Nanes MS. Declining bone mass in men with chronic pulmonary disease: contribution of glucocorticoid treatment, body mass index, and gonadal function. Chest 1999;116:1616-1624.

5. Shane E, Silverberg SJ, Donovan D, et al. Osteoporosis in lung transplantation candidates with end-stage pulmonary disease. Am J Med 1996;101:262-269.

6. Incalzi RA, Caradonna P, Ranieri P, et al. Correlates of osteoporosis in chronic obstructive pulmonary disease. Respir Med 2000;94:1079-1084.
7. Graat-Verboom L, Wouters EF, Smeenk FW, van den Borne BE, Lunde R, Spruit MA. Current status of research on osteoporosis in COPD: a systematic review. Eur Respir J 2009;34:209-218.

8. Lekamwasam S, Trivedi DP, Khaw KT. An association between respiratory function and bone mineral density in women from the general community: a cross sectional study. Osteoporos Int 2002;13:710-715.

9. Biskobing DM. COPD and osteoporosis. Chest 2002; 121:609-620.

10. Shepherd AJ, Cass AR, Carlson CA, Ray L. Development and internal validation of the male osteoporosis risk estimation score. Ann Fam Med 2007;5:540-546.

11. Choi JW, Pai SH. Association between respiratory function and osteoporosis in pre- and postmenopausal women. Maturitas 2004;48:253-258.

12. Lekamwasam S, Trivedi DP, Khaw KT. An association between respiratory function and hip bone mineral density in older men: a cross-sectional study. Osteoporos Int 2005;16:204-207.

13. Sin DD, Man JP, Man SF. The risk of osteoporosis in Caucasian men and women with obstructive airways disease. Am J Med 2003;114:10-14.

14. Riancho JA, Gonzalez Macias J, Del Arco C, Amado JA, Freijanes J, Anton MA. Vertebral compression fractures and mineral metabolism in chronic obstructive lung disease. Thorax 1987;42:962-966.

15. Karadag F, Cildag O, Yurekli Y, Gurgey O. Should COPD patients be routinely evaluated for bone mineral density? J Bone Miner Metab 2003;21:242-246.

16. Schols AM, Broekhuizen R, Weling-Scheepers CA, Wouters EF. Body composition and mortality in chronic obstructive pulmonary disease. Am J Clin Nutr 2005;82:5359.

17. Bolton CE, Ionescu AA, Shiels KM, et al. Associated loss of fat-free mass and bone mineral density in chronic obstructive pulmonary disease. Am J Respir Crit Care Med 2004;170:1286-1293.

18. Slinde F, Gronberg A, Engstrom CP, Rossander-Hulthen L, Larsson S. Body composition by bioelectrical impedance predicts mortality in chronic obstructive pulmonary disease patients. Respir Med 2005;99:1004-1009.

19. Black PN, Scragg R. Relationship between serum 25-hydroxyvitamin $\mathrm{D}$ and pulmonary function in the third national health and nutrition examination survey. Chest 2005;128:3792-3798. 
20. Bolotin HH. DXA in vivo BMD methodology: an erroneous and misleading research and clinical gauge of bone mineral status, bone fragility, and bone remodelling. Bone 2007;41:138-154.

21. El Maghraoui A, Roux C. DXA scanning in clinical practice. QJM 2008;101:605-617.

22. Ferguson GT, Calverley PM, Anderson JA, et al. Preva- lence and progression of osteoporosis in patients with COPD: results from the towards a revolution in COPD health study. Chest 2009;136:1456-1465.

23. Smith BJ, Laslett LL, Pile KD, et al. Randomized controlled trial of alendronate in airways disease and low bone mineral density. Chron Respir Dis 2004;1:131-137. 